\title{
SYNTHETIC VISION SYSTEMS
}

\section{L.J. Prinzel and L.J. Kramer}

Research and Technology Directorate, Crew Systems and Operations Branch (D-318), Mail Stop 152, NASA Langley Research Center, Hampton, VA 23681, USA

\section{INTRODUCTION}

A "synthetic vision system" is an aircraft cockpit display technology that presents the visual environment external to the aircraft using computer-generated imagery in a manner analogous to how it would appear to the pilot if forward visibility were not restricted. The purpose of this chapter is to review the state of synthetic vision systems, and discuss selected human factors issues that should be considered when designing such displays.

\subsection{Background}

Aviation has been witness to the introduction of many new avionics systems (e.g., attitude indicators, radio navigation, instrument landing systems, ground proximity warning systems) that have sought to overcome the issues associated with limited outside visibility for the pilot. Still, limited visibility remains the single most critical factor affecting both safety and capacity in worldwide aviation operations. In commercial aviation alone, over $30 \%$ of fatal accidents worldwide are categorized as Controlled Flight Into Terrain (CFIT), where a normally functionally, mechanically sound aircraft impacts terrain or obstacles that the flight crew could not see due to the lack of outside visual reference or impaired crew terrain/hazard situational awareness. In general aviation, the largest accident category is Continued Flight into Instrument Meteorological Conditions, in which a non-instrument rated pilot continues to fly into deteriorating weather and visibility, leading to a loss of the visual horizon and a potential impact into unexpected terrain or spatial disorientation and loss of control. Finally, the greatest factor affecting airport delays is limited visibility that reduces runway capacity and increases distances required for air traffic separation when weather conditions drop below visual flight rule operations.

Synthetic vision is a visibility solution to this visibility problem that would allow all aircraft to be flown under the virtual equivalent of visual meteorological conditions or clear daylight operations.

\section{DEFINITIONS}

\subsection{Enhanced Vision}

Past solutions to enhance pilot visibility have been sought through imaging sensors. Such systems are termed "enhanced vision systems" and consist of active or passive sensors that are used to penetrate weather phenomena such as darkness, fog, haze, rain, and snow. Enhanced vision systems have been installed on military aircraft but are infrequently found on commercial transport aircraft due to cost, complexity, and technical 
performance. Enhanced vision sensor imagery depends upon the external environment and the sensor characteristics. For example, high-frequency radars (e.g., $94 \mathrm{GHz}$ ) and infrared sensors may exhibit degraded range performance in heavy precipitation and certain fog types. On the other hand, low-frequency (e.g., 9.6 GHz) and mid-frequency (e.g., $35 \mathrm{GHz}$ ) radars have improved range, but often have poor display resolution. Active radar sensors can suffer from mutual interference when multiple users are in close proximity. Finally, present enhanced vision sensors do not extract color attributes which may potentially create misleading visual artifacts under certain temperature or radar reflective conditions.

\subsection{Synthetic Vision}

A "synthetic vision system" is an electronic means of displaying the pertinent and critical features of the environment external to the aircraft through a computer-generated image of the external scene topography using on-board databases (e.g., terrain, obstacles, cultural features), precise positioning information, and flight display symbologies that may be combined with information derived from a weather-penetrating sensor (e.g., runway edge detection, object detection algorithms) or with actual imagery from enhanced vision sensors.

All aircraft categories can benefit from synthetic vision system applications, including general aviation aircraft, business jets, cargo and commercial airliners, military cargo and fighter jets, and rotorcraft. These systems may be shown on head-down, head-up, helmet-mounted, and navigation displays and be combined with runway incursion prevention technology; database integrity monitoring equipment; enhanced vision sensors; taxi navigation and surface guidance maps; advanced communication, navigation, and surveillance technologies; and traffic and hazard display overlays. What characterizes the Synthetic Vision Systems technology is the intuitive representation of visual information and cues that the pilot or flight crews would normally have in day, visual meteorological conditions. 


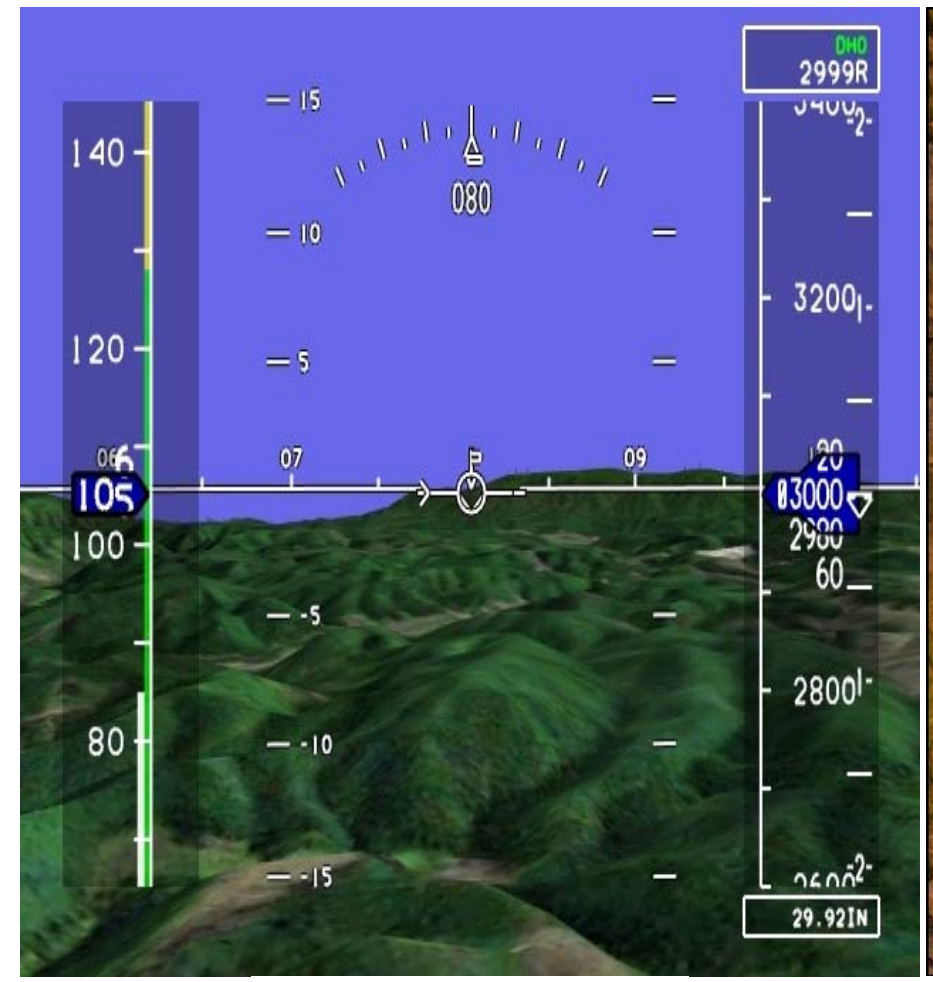

Primary Flight Display

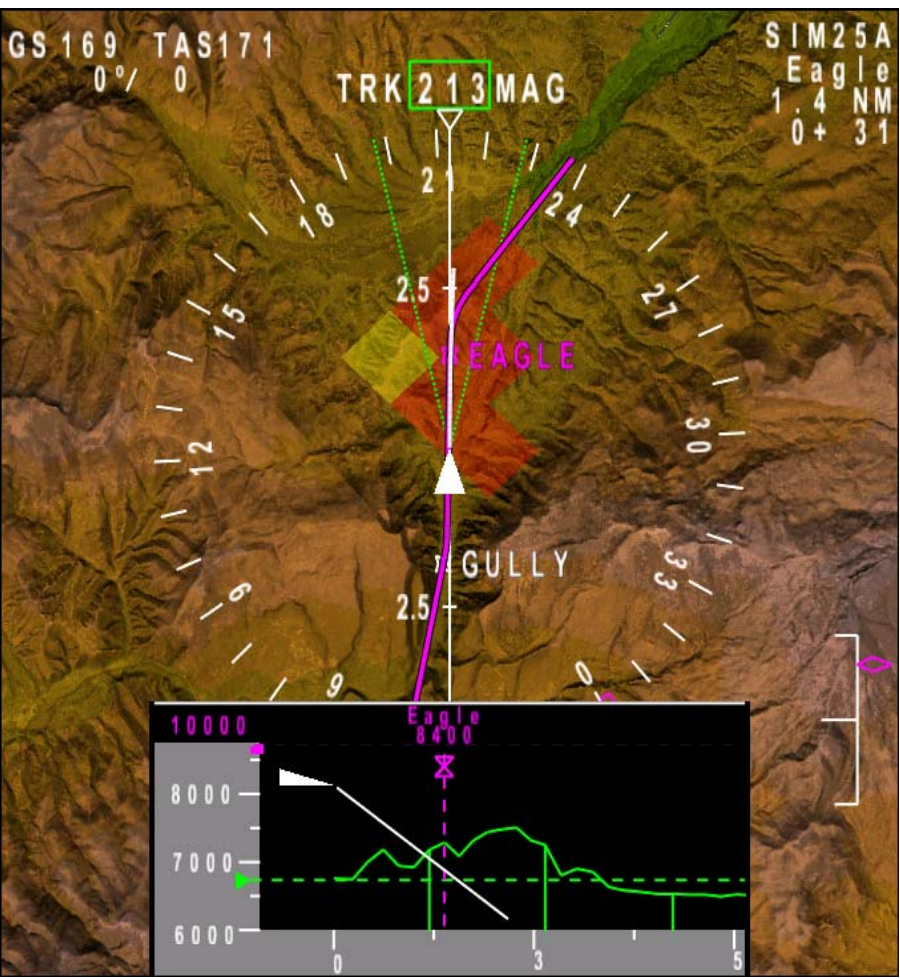

Navigation Display

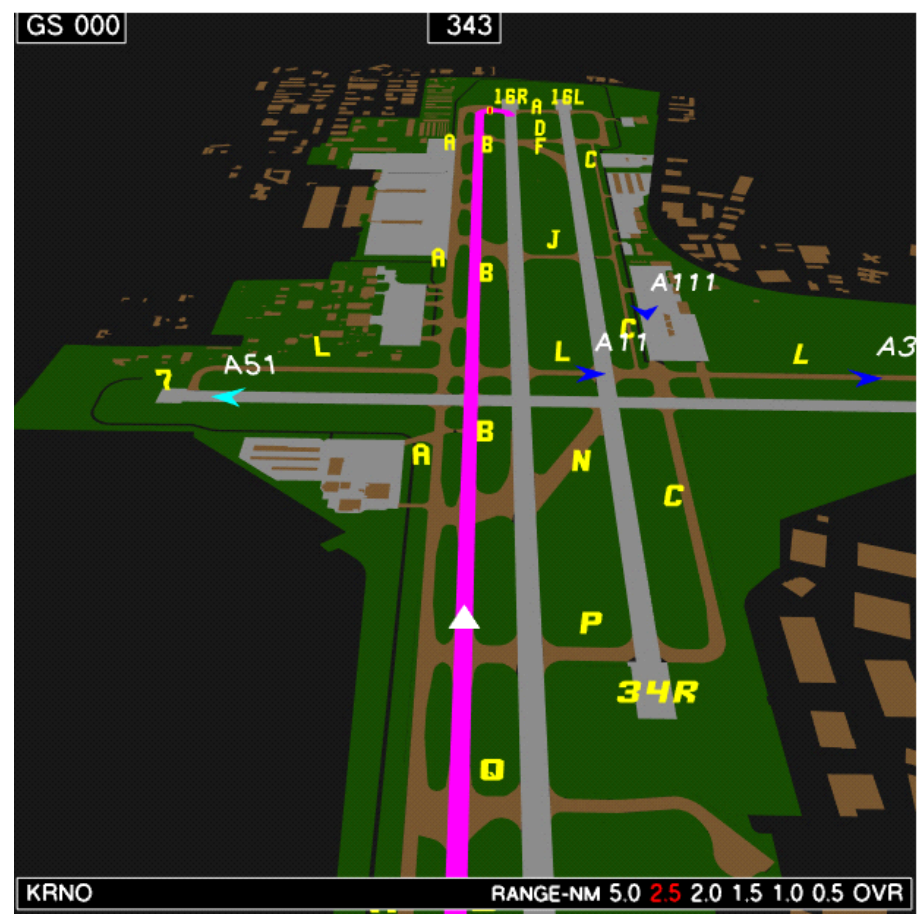

Surface Guidance Map Display

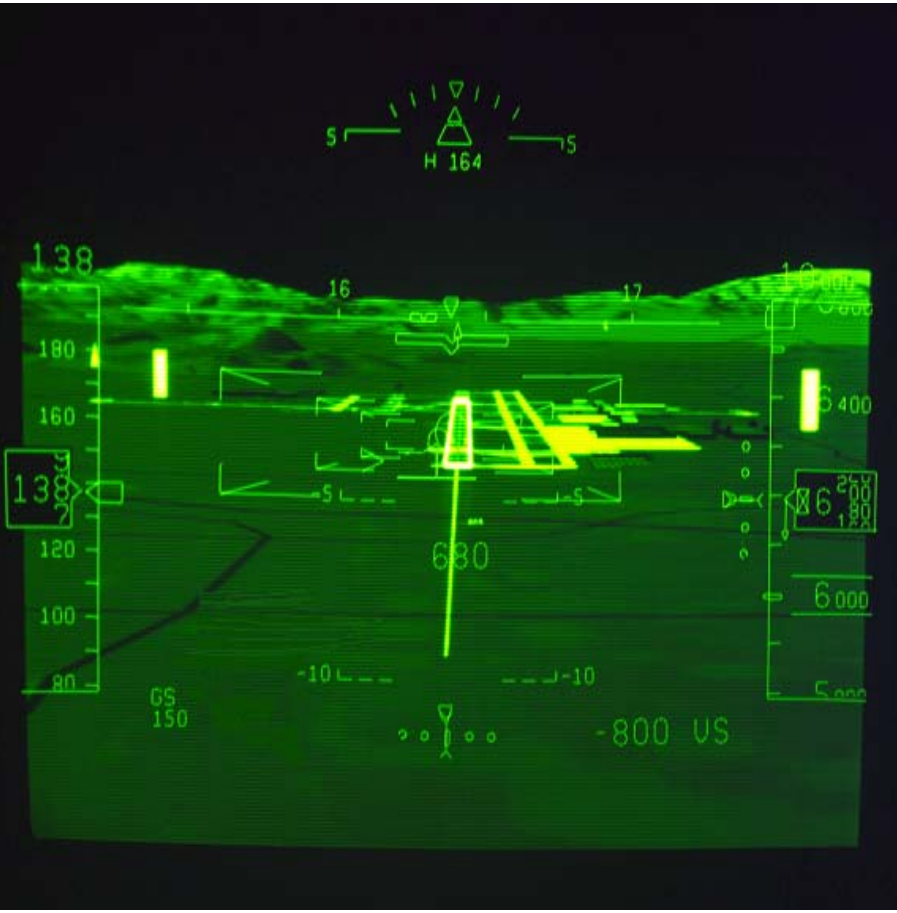

Head-Up Display

Figure 1. Examples of Synthetic Vision System Displays 


\section{DESCRIPTION}

\subsection{Enabling Technologies}

Several research and technological developments have made synthetic vision systems possible. Fundamentally, these systems require only precise ownship location, a database, available graphics and computing capability and display media. Additional information and capability may be required depending upon the intended function. Many technical breakthroughs are responsible for the growing efficacy of synthetic vision systems, which include:

- Head-Up Display and Helmet-Mounted Display development

- Efficient and effective display symbology and presentation format development, including Pathway/Tunnel/Highway-In-The-Sky development and ground operations displays.

- Global Positioning System/Inertial Navigation System (GPS/INS) development

- Mapping, Charting, \& Geodesy Enhancements, Including Shuttle Radar Topography Mission (SRTM) and published, accepted standards (e.g., RTCA DO-255, -272, -276, -291)

- Datalink capability (ADS-B, CPDLC, TIS-B), enabling Cockpit Display of Traffic Information (CDTI), Runway Incursion Prevention System (RIPS) and digital transmission of Air Traffic Control instructions.

- Improved computer processing and graphic processors

- Database Integrity Monitoring Equipment (DIME) development

- Enhanced Vision System imaging sensors

\subsection{Synthetic Vision System Elements}

The synthetic vision system is composed of four elements: Enhanced intuitive view, hazard detection and display, integrity monitoring and alerting, and precision navigation guidance.

(a) Enhanced Intuitive View --- Synthetic vision systems present the display of pertinent and critical features of the environment external to the aircraft through computergenerated imagery particularly when weather conditions prevent the pilot from effectively seeing these factors through the cockpit window. The display is intuitive because it displays these data in the way that the pilot normally would see in day visual meteorological conditions and includes symbology that reduces flight technical error and fosters instant recognition and awareness.

(b) Hazard Detection and Display --- Terrain, cultural, traffic, obstacles, and other hazards are graphically represented to the pilot to maintain the pilot's situation awareness and proactively ensure terrain and hazard separation. Synthetic vision systems provide for pilot detection, identification, geometry awareness, prioritization, action decision and assessment, and overall situation awareness not afforded by today's avionics which require the pilot to be reactive to alert cautions and warnings. 
(c) Integrity Monitoring and Alerting --- Some level of integrity monitoring and alerting is required in all SVS applications because pilots must trust that the synthetic vision system provides an accurate portrayal (i.e., not hazardly misleading information). A flight-critical level of integrity, redundancy, and the inclusion of reversionary modes may be needed to achieve the ultimate potential for a Synthetic Vision System. In this case, independent sources to verify and validate the synthetic vision presentation (e.g., radar altimeters, enhanced vision sensors, TAWS) fashioned to create integrity monitoring functions may be necessary. If the integrity monitoring discovers a mismatch, the displays degrade gracefully to reversionary modes and trigger an alert to the pilot that synthetic vision is no longer available nor reliable. The system effectively prevents a pilot from using erroneous or misleading synthetic vision information.

(d) Precision Navigation Guidance --- Synthetic vision system elements (e.g., surface guidance, taxi maps, tunnels/pathways/highways-in-the-sky, velocity vectors, command guidance cues) allow pilots to rapidly and accurately correlate ownship position to relevant terrain, desired flight paths/plans, cultural features, and obstacles. These elements enable the pilot to monitor navigation precision to meet Required Navigation Performance (RNP) criteria and compliance with complex approach and departure procedures (RNAV, GLS, curved, step-down, noise abatement) without the need for land-based navigation aids (e.g., ILS, VOR, DME, ADF, NDB, LORAN) that are expensive to install and maintain.

\subsection{Synthetic Vision System Components}

There are many potential conceptualizations of synthetic vision systems dependent upon the class of aircraft (CFR Title 14 Parts 23, 25, 27, 29) to which the system is being designed. As an example, the National Aeronautics and Space Administration (NASA) synthetic vision system concept for Part 25 aircraft has the following synthetic vision system components:

Synthetic Vision Database/Sensors

- On-board synthetic vision databases

- Weather Radar

- Radar altimeter

- Forward Looking Infrared (option)

- Millimeter Wave Radar (option)

Synthetic Vision Displays

- Primary Flight Display, or imbedded display features

- Navigation Display, or display features/pages

- Interface with other cockpit displays, e.g., TAWS

- Head-Up or Helmet-Mounted Displays (option)

Computers/Embedded Computational Functions

- Image Object Detection and Fusion

- Data confidence, detection threshold filtering, expected error 
- Source data reasonability and integrity estimation

- Hazard detection

- Data fusion (correlated position of potential hazards)

- Image enhancement and fusion, where appropriate

- Integrity self monitoring and alerting

- System Integrity, Verification and Validation

- Database reliability, integrity, expected error

- Other source data reasonability and integrity estimation

- Generate appropriate system alert messages

- Integrity self monitoring and alerting

- Computations and Symbology Generation

- Cleared and actual path depiction

- Hazard element display integration and depiction

- Runway Incursion Prevention System

- Hold Short and Landing Technology

- Navigation and hazard situation awareness enhanced display elements

- Alert and warning generation and presentation

- Overall display symbol generation and/or integration

- Integrity self monitoring and alerting

Equipment

- Dedicated synthetic vision system support equipment and crew interfaces

- Interface with other aircraft systems

Associated Aircraft Systems

- Differential Global Positioning System

- Inertial Reference Unit/Attitude Heading Reference Set (IRU/AHRS)

- Air Data Computer (ADC)

- Radio

- RADAR

- Traffic Collision and Avoidance System (TCAS)

- Data Link aggregate (e.g., IFF Mode S, ADS-B)

- Terrain Awareness and Warning System (TAWS)

- Laser Altimeter (option) 


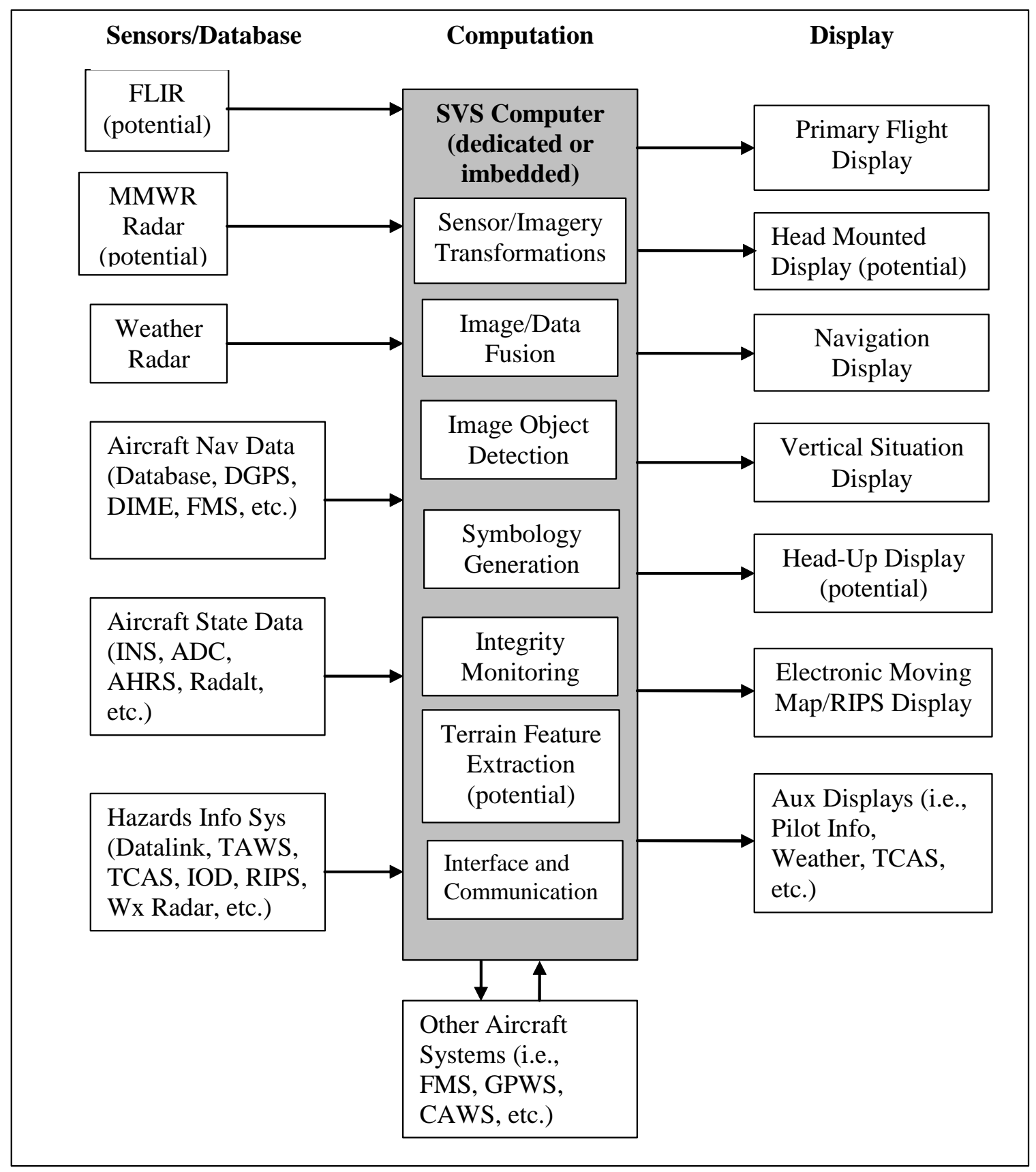

Figure 2. NASA Synthetic Vision Concept 


\section{BENEFITS}

\subsection{Safety Benefits}

Synthetic Vision Systems are characterized by the ability to represent visual information and cues of the environment external to the aircraft that are intuitive and resemble visual flight conditions with unlimited ceiling and visibility. In terms of safety benefits, synthetic vision may help to reduce many accident precursors including:

- Loss of vertical and lateral path and terrain awareness

- Loss of terrain and traffic awareness

- Unclear escape or go-around path even after recognition of problem

- Loss of altitude awareness

- Loss of situation awareness relating to the runway environment and incursions

- Unclear path guidance on the surface

- Unusual attitude / upset recognition

- Runway incursions

- Non-compliance with Air Traffic Control (ATC) clearances

- Transition from instruments to visual flight

- Spatial disorientation

These safety benefits are particularly evident during non-normal and emergency situations. In these non-normal events, mental workload and tasking/attentional demands placed on the pilot are high. Synthetic vision systems, through their intuitive display and presentation methods, off-load the pilots from basic spatial awareness tasking (to avoid terrain, traffic, and obstacles) and increase their speed of situation recognition.

\subsection{Operational Benefits}

The aviation safety benefits alone of synthetic vision may be reason enough to pursue the technology, but operational and economic benefits must be considered for Part 121 and 135 operations because of the costs associated with implementation of these systems. Analyses have demonstrated that synthetic vision could serve to increase national airspace system capacity by providing the potential for increased visual-like operations gate-to-gate even under extreme visibility restricted weather conditions (e.g., Category IIIb minimums). For example, a NASA-sponsored cost-benefit analysis of 10 major US airports calculated the average cost savings to airlines for the years 2006 to 2015 to be $\$ 2.25$ Billion. While these savings are predicated on several technology developments and success implementation/certification, this analysis indicates the potential order of magnitude savings and operational efficiencies offered by these technologies. Operational benefits of synthetic vision systems may include:

- Intuitive depiction of ATC cleared flight paths and taxi clearances

- Enhanced surface operations (e.g., rollout, turn off and hold short, taxi)

- Reduced runway occupancy time in low visibility 
- Reduced departure and arrival minimums

- Better allow for converging and circling approaches, especially for dual and triple runway configurations

- Reduce inter-arrival separations

- Provide for independent operations on closely-spaced parallel runways

- Provide for precise noise abatement operations

- Required Navigation Performance adherence

- 4D navigation capability

- Oceanic route optimization, spacing, and ownship reporting

- Enhanced path guidance, compliance monitoring, and alerting

- Depiction of terminal, restricted and special use airspace

- Depiction of traffic and weather hazards and resolutions

- Mission planning / rehearsal capability

- Reduced training requirements

- Approach operations to Type I and non-ILS runways

- Virtual visual self-spacing and station keeping capability

- Piloting aid support (e.g., flare guidance, runway remaining, navigation guidance)

- Enhanced flight management

\section{ONGOING RESEARCH EFFORTS}

\subsection{Government Research}

There are several government research efforts to design synthetic vision systems. NASA is pursuing research and development for commercial, business, and general aviation aircraft. The project is funded under the Aviation Safety and Security program, Synthetic Vision Systems research project principally conducted at the NASA Langley Research Center. Human performance modeling and synthetic vision rotocraft research (joint Army-NASA project) are also conducted at the NASA Ames Research Center. The Federal Aviation Administration (FAA) Capstone program focuses on synthetic vision technology that together with NASA, the Alaskan community and aviation industry partners, seeks to reduce Part 91 general aviation accidents. The Air Force Research Laboratory Human Effectiveness Directorate is evaluating synthetic vision technology displays to enable U.S. Air Force aircraft to fly with high situation awareness under instrument meteorological conditions and help prevent CFIT accidents. Finally, there has been a significant amount of synthetic vision research conducted by international government research agencies (e.g., Germany Aerospace Center, National Aerospace Laboratory).

\subsection{Industry Research}

Industry research has partnered with government agencies to pursue development of synthetic vision systems. Rockwell-Collins and BAE Systems have significant research efforts toward commercial and military applications of synthetic vision, enhanced vision, and sensor fusion technology. Part 23 aircraft are served by several companies most 
notably Universal, Chelton Flight Systems, and RTI International. Universal has received a FAA technical standard order for the Vision-1 egocentric and exocentric synthetic vision system displays. Chelton Flight Systems was selected for the FAA Capstone program and has received Supplemental Type Certification (STC) approval for installation of synthetic vision EFIS in the Cessna Citation 501, King Air 90/100/200/300, Conquest I and II, all Cheyenne, all Commander, MU-2, Pilatus PC-12, TBM-700, Piaggio Avanti, and hundreds of other aircraft, including helicopters. Finally, RTI International has integrated a 3-D virtual display depicting the flight path, a worldwide terrain database, weather and traffic information, and GPS technology into a single cockpit instrument that shows traffic, weather, obstacles, flight path, and navigation information.

\subsection{University Research}

Numerous university researchers have contributed to the growing knowledge of the human factors of synthetic vision displays. For example, research conducted by Christopher Wickens (University of Illinois at Urbana-Champaign), Eric Theunissen (Technical University of Delft), Thomas Schnell (University of Iowa), Kevin Corker (San Jose State University), Jacques Verly (University of Liege), Maarten Uijt De Haag (Ohio State University), and Andrew Barrows (Stanford University) are a few of the many who have significantly advanced the understanding of human factors issues.

\section{SELECT HUMAN FACTORS ISSUES}

A Human Factors and Ergonomics conference panel was held at the Human Facotrs and Ergonomics Annual Meeting in 2004 to debate the human factors of synthetic vision systems. The panel members were Lawrence Prinzel (NASA), Raymond Comstock (NASA), Mica Endsley (SA Technologies), Christopher Wickens (UIUC), Kevin Corker (San Jose State U.), Tim Etherington (Rockwell-Collins), Guy French (Wright-Patterson AFB), and Michael Snow (Boeing). The consensus of the panel was that synthetic vision systems have significant promise in achieving the aforementioned safety and operational benefits. It was acknowledged that significant human factors research has been conducted, but a number of human factors issues still remain.

Corker and Guneratne (2002) categorized the human factors issues into three research areas: Image quality, information integration, and operational concepts. Based on a literature review, they developed an extensive list of human factors issues and provided a set of research priority recommendations which are presented below.

\subsection{Image Quality}

\begin{tabular}{|c|l|}
\hline $\begin{array}{c}\text { Human Factors } \\
\text { Issue }\end{array}$ & \multicolumn{1}{|c|}{ Research Recommendation } \\
\hline $\begin{array}{c}\text { Field-of-View } \\
\text { Display Size }\end{array}$ & $\begin{array}{l}\text { What are the effects of display minification? Should field-of- } \\
\text { view be automatically or manually determined? Can synthetic } \\
\text { vision be retrofitted into smaller cockpit display sizes? Should }\end{array}$ \\
\hline
\end{tabular}




\begin{tabular}{|c|l|}
\hline \multirow{5}{*}{ Clutter } & $\begin{array}{l}\text { different field-of-view options be made available? What are the } \\
\text { minimum and maximum field-of-view settings for each display } \\
\text { size? }\end{array}$ \\
\hline \multirow{5}{*}{ Iconography } & $\begin{array}{l}\text { What is the minimum number of curves or objects required to } \\
\text { convey given information? How can the data be arranged to } \\
\text { provide a clear view without obstructing the view? How can } \\
\text { clutter be quantified on synthetic vision displays? What are the } \\
\text { effects of non-iconic information and synthetic vision } \\
\text { presentation on pilot scan of the cockpit and out-the-window } \\
\text { environment? }\end{array}$ \\
\hline Display Contrast \\
$\begin{array}{l}\text { What are effective symbol sizes for iconic representations of } \\
\text { obstacles, traffic, guidance cues, etc.? What colors and standards } \\
\text { should be used? What are the minimum resolution, brightness, } \\
\text { and contrast? What conventions (color, size, shape, etc.) can be } \\
\text { carried forward to support visual momentum and quick transition } \\
\text { between synthetic vision and traditional instrumentation? }\end{array}$ \\
\hline $\begin{array}{l}\text { What is the minimum contrast necessary to convey synthetic } \\
\text { terrain information? Should contrast be automatically adjusted for } \\
\text { lighting conditions and/or background colors? Should contrast } \\
\text { control be given to pilots? }\end{array}$ \\
\hline Opacity \\
$\begin{array}{l}\text { Should HUD symbology and/or synthetic terrain be entirely } \\
\text { opaque, transparent, or mixed? Should transparency be varied } \\
\text { with lighting conditions? What are the effects of weather and } \\
\text { lighting transitions? }\end{array}$ \\
\hline
\end{tabular}

\subsection{Information Integration}

\begin{tabular}{|c|l|}
\hline $\begin{array}{c}\text { Human Factors } \\
\text { Issue }\end{array}$ & \multicolumn{1}{|c|}{ Research Recommendation } \\
\hline Guidance & $\begin{array}{l}\text { How should pathway guidance formats be designed for synthetic } \\
\text { vision systems? What are the best guidance cues for predictor } \\
\text { vector information? }\end{array}$ \\
\hline Terrain & $\begin{array}{l}\text { What are the best synthetic terrain formats? What level of } \\
\text { realism is required for effective synthetic vision systems? Would } \\
\text { photo-realism be sufficient for altitude and trend information to } \\
\text { lead the crew to a false confidence in the system? Should } \\
\text { wireframe formats and overlays be used? What amount of } \\
\text { texturing and object detail is needed to provide adequate depth- } \\
\text { cueing? What would be the effect of combining display terrain } \\
\text { texturing methods? }\end{array}$ \\
\hline Cognitive & $\begin{array}{l}\text { Will realistic terrain cause the pilot to focus on the artificial } \\
\text { display to the exclusion of the outside world and backup } \\
\text { instruments? Will synthetic vision displays be compelling and } \\
\text { induce complacency? }\end{array}$ \\
\hline Tunneling & $\begin{array}{l}\text { What is the best way of integrating synthetic vision systems with } \\
\text { existing traffic, terrain, and other warning displays? }\end{array}$ \\
\hline Display Integrations
\end{tabular}




\begin{tabular}{|c|l|}
\hline Trend Information & $\begin{array}{l}\text { How can synthetic vision better impart awareness of trends such } \\
\text { as shallow climbing, descending, etc.? What is the best mix of } \\
\text { trend and guidance information to avoid clutter? }\end{array}$ \\
\hline Skill Retention & $\begin{array}{l}\text { How does a synthetic vision system change a pilot's interaction } \\
\text { with tradition instruments? Do pilots retain the skills necessary to } \\
\text { revert back to traditional instruments if the system fails? }\end{array}$ \\
\hline Workload Demand mental & $\begin{array}{l}\text { Will synthetic vision create a measurable decrease in mental } \\
\text { workload? What is the effect of the increase in data information } \\
\text { afforded by synthetic vision displays in the cockpit? }\end{array}$ \\
\hline
\end{tabular}

\subsection{Operational Concepts}

\begin{tabular}{|c|c|}
\hline $\begin{array}{l}\text { Human Factors } \\
\text { Issue }\end{array}$ & Research Recommendation \\
\hline $\begin{array}{l}\text { Flight Phase } \\
\text { Transitions }\end{array}$ & $\begin{array}{l}\text { Which transitions will require switching between synthetic vision } \\
\text { and other instrumentation? How can synthetic vision be designed } \\
\text { to minimize the effect of the transitions? }\end{array}$ \\
\hline Crew Interaction & $\begin{array}{l}\text { Should synthetic vision be designed to accommodate current } \\
\text { operational procedures? Should pilot-flying or pilot-not-flying } \\
\text { have different displays for their different roles? Or should they } \\
\text { have the same displays for cross-checking? How much effort can } \\
\text { be taken from aircraft management for display management? }\end{array}$ \\
\hline Failure Modes & $\begin{array}{l}\text { When should the crew be alerted to potential failures? Too many } \\
\text { alarms may cause an impression that the system is "buggy"; } \\
\text { delaying an alert too long may leave the crew too little time to } \\
\text { react to a dangerous system. What is the best way to alert the } \\
\text { crew visually, aurally, or otherwise in a way that is clearly } \\
\text { distinguishable from the other cockpit alarms? }\end{array}$ \\
\hline $\begin{array}{l}\text { Essential } \\
\text { Information }\end{array}$ & $\begin{array}{l}\text { What information is absolutely necessary for which phases of } \\
\text { flight? Should there be distinctly different sets of data for } \\
\text { different phases, as the PFD has different modes? Should these } \\
\text { modes be automatically set, or should the crew have the } \\
\text { capability to determine the mode? }\end{array}$ \\
\hline $\begin{array}{l}\text { Effect at Various } \\
\text { Workloads }\end{array}$ & $\begin{array}{l}\text { Does synthetic vision provide a benefit during both high and low } \\
\text { workload? Are there problems with low workload over long } \\
\text { periods of time? }\end{array}$ \\
\hline $\begin{array}{c}\text { Crew Confidence in } \\
\text { System }\end{array}$ & $\begin{array}{l}\text { Does synthetic vision lend itself to overtrust and complacency? } \\
\text { What factors are most important to convincing pilots that it is safe } \\
\text { to follow synthetic vision display and guidance? What operating } \\
\text { characteristics are likely to decrease confidence (e.g., minimum } \\
\text { frame rates, power losses, sensor lag)? What is the proper } \\
\text { balance of crew confidence in the system and ensuring that cross- } \\
\text { checking other instruments is performed? }\end{array}$ \\
\hline $\begin{array}{c}\text { Resource } \\
\text { Management }\end{array}$ & $\begin{array}{l}\text { How much control should pilots have over the synthetic vision } \\
\text { system during flight? }\end{array}$ \\
\hline
\end{tabular}




\section{CONCLUSIONS}

Commercial aviation is among the safest modes of transportation. But, the need to fly regardless of the weather has led to an accident rate that is far from ideal. Aircraft accidents serve as powerful reminders of the risks involved and how much safer flying can and should be. Technology has advanced to allow for the emergence of synthetic vision systems that will fundamentally change how aircraft are operated in instrument conditions. By creating a virtual visual meteorological condition, synthetic vision holds the promise to eliminate the precursor to many accidents and incidents (limited visibility) and substantially improve the safety and operational efficiency of aviation.

\section{ACKNOWLEDGEMENTS}

The authors gratefully acknowledge the assistance of Randall Bailey and Dan Williams (NASA Langley Research Center), R. Michael Norman (Boeing), and Kevin Corker (San Jose State University).

\section{RECOMMENDED FURTHER READINGS}

Corker, K.M., \& Guneratne, E. (2002). Human factors issues and evaluation of commercial and business aircraft synthetic vision systems. NASA Contractor Final Report (21-1214-2882).

Parrish, R.V., Baize, D.G., \& Lewis, M.S. (2001). Synthetic vision. In C. Spitzer (Ed.), The Avionics Handbook (pp. 16-1 - 16-8). CRC Press: Boca Raton

Prinzel, L.J., Comstock, J.R., Corker, K.M., Endsley, M.R., Etherington, T., French, G.A., Snow, M.P., Wicken, C.D. (2004). Human factors of synthetic vision systems. Proceedings of the Annual Meeting of the Human Factors and Ergonomics Society, 48.

Prinzel, L.J., Comstock, J.R., Glaab, L.J., Kramer, L.J., Arthur, J.J., \& Barry, J.S. (2004). The efficacy of head-down and head-up synthetic vision display concepts for retro- and forward-fit of commercial aircraft. International Journal of Aviation Psychology, 14(1), 53-77.

Prinzel, L.J., Hughes, M.F., Arthur, J.J., Kramer, L.J., Glaab, L.J., Bailey, R.E., Parrish, R.V., \& Uenking, M.D. (2003). Synthetic Vision CFIT Experiments for GA and Commercial Aircraft: "A Picture Is Worth A Thousand Lives”. Proceedings of the Human Factors \& Ergonomics Society, 47, 164-168.

Prinzel, L.J., Kramer, L.J., Arthur, J.J., Bailey, R.E., Comstock, J.R. (2004). Comparison of head-up and head-down "highway-in-the-sky" tunnel and guidance concepts for synthetic vision displays. Proceedings of the Annual Meeting of the Human Factors and Ergonomics Society, 48. 
Prinzel, L.J., Kramer, L.J., Comstock, J.R., Bailey, R.E., Hughes, M.F., \& Parrish, R.V. (2002). NASA synthetic vision EGE flight test. Proceedings of the Annual Human Factors and Ergonomics Meeting, 46, 135-139.

Schnell, T., Kwon, Y., Merchant, S., \& Etherington, T. (2004). Improved flight technical performance in flight decks equipped with synthetic vision information system displays. International Journal of Aviation Psychology, 14(1), 79-102.

Snow, M.P., \& French, G.A. (2001). Human factors in head-up synthetic vision display. SAE Technical Paper 2001-01-2652. Warrendale, PA: Society of Automotive Engineers.

Snow, M. P., and Reising, J. M. (1999). Effect of pathway-in-the-sky and synthetic terrain imagery on situation awareness in a simulated low-level ingress scenario. Proceedings of the $4^{\text {th }}$ Annual Symposium on Situation Awareness in the Tactical Air Environment (pp. 198-207). Patuxent River, MD: NAWCAD.

Theunissen, E. (1997). Integrated design of a man-machine interface for 4-D navigation. Netherlands: Delft University Press.

Uijt de Haag, M., Young, S., Sayre, J., Campbell, J., \& Vadlamani, A. (2002). DEM integrity monitor equipment (DIME) flight test results. In J.G. Verly (Ed.), Enhanced and Synthetic Vision 2002 (pp. 72-83). Bellingham, Washington: International Society for Optical Engineering (SPIE).

Williams, D., Waller, M., Koelling, J., Burdette, D., Doyle, T., Capron, W., Barry, J., \& Gifford, R. (2001). Concept of operations for commercial and business aircraft synthetic vision systems. NASA Langley Research Center: NASA Technical Memorandum TM-2001-211058.

Wickens, C.D., Alexander, A.L., \& Hardy, T.J. (2003). The primary flight display and Its pathway guidance: Workload, performance, and situation awareness. Final Technical Report AHFD-03-2/NASA-03-1. Savoy, Ill: University of Illinois, Aviation Research Laboratory.

Wickens, C.D., Alexander, A.L., Thomas, L.C., Horrey, W.J., Nunes, A., Hardy, T.J., Zheng, S.X. (2004). Traffic and flight guidance depiction on a synthetic vision system display: The effects of clutter on performance and visual attention allocation. Final Technical Report AHFD-04-10/NASA-04-1. Savoy, Ill: University of Illinois, Aviation Research Laboratory.

Verly, J.G. (Ed.). (1997 - 2004), Enhanced and Synthetic Vision (Vols. 1997 2004). Bellingham, WA: International Society of Optical Engineering. 